\title{
Reference equations for lung function screening of healthy never-smoking adults aged $18-80$ years
}

\author{
S.P. Kuster*, $f$, D. Kuster*,, C. Schindler", M.K. Rochat ${ }^{\star}$, J. Braun ${ }^{+}$, \\ L. Held ${ }^{+}$and O. Brändli ${ }^{\S}$
}

ABSTRACT: The need for updated spirometric reference values to be used on European populations is widely acknowledged, especially for subjects aged $>\mathbf{7 0}$ yrs. Their reference values are generally based on extrapolations. The aim of the present study was to calculate reference values for lung function screening of healthy, never-smoking adults aged 18-80 yrs and to compare them with the most widely used reference equations.

Results of screening spirometry of $\mathbf{8 , 6 8 4}$ healthy, never-smoking adults were used to calculate mean values and fifth percentiles of lung function variables.

The European Community of Coal and Steel (ECCS) reference equations underestimate forced expiratory volume in one second (FEV1) and forced vital capacity (FVC). For example, in 50-yr-old males (height $175 \mathrm{~cm}$ ), lower limits of normal for FEV1 are underestimated by $198 \mathrm{~mL}$, and for FVC by $210 \mathrm{~mL}$. In 50-yr-old females (height $165 \mathrm{~cm}$ ), lower limits of normal for FEV1 are underestimated by $191 \mathrm{~mL}$, and for FVC by $270 \mathrm{~mL}$. The decline of FVC in elderly subjects is steeper than predicted by the ECCS.

Reference equations derived from spirometry data locally collected in a practical setting by well-trained personnel might be more appropriate for everyday use than generally used equations based on data from scientific studies in the distant past.

\section{KEYWORDS: Aged, pulmonary function, reference equations, spirometry}

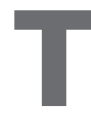
he comparison of results of lung function tests with normal values may influence decisions that have important implications both for individuals and for the healthcare system. Several sets of normal values have been published over the last decades and "normality" for a given age and height varies considerably across these studies. Such variations may be explained by the selection criteria of "normal" populations, cohort effects, measurement techniques and devices, biological variability across populations and statistical modelling [1-3]. Major arguments for updating reference values on a regular basis are birth cohort effects (e.g. changes in the distribution of lung function at a given age over time) and new technical equipment [4]. If no updating is performed, normal values may gradually lose their sensitivity in detecting abnormal conditions at an early stage.

Standardisation procedures have been improved and computer-based equipment allows ad hoc decisions with regard to acceptability and reproducibility of spirometric manoeuvres $[5,6]$.

The European Community of Coal and Steel (ECCS) prediction equations, which are most widely used in Europe, were derived from lung function measurements of subjects, including smokers, studied in the years 1954-1980, from different study populations and from several data sets. Thus their value for the interpretation of spirometric tests has been challenged [7-9]. Current guidelines do not recommend a specific set of equations for use in Europe. There is a major need for new studies to derive updated reference equations for lung function, especially for elderly persons [10]. Recent recommendations on equipment and standardisation of procedures propose reference values based on cross-sectional studies of lifetime nonsmokers [2, 5, 8]. It has been shown that wheeze, breathlessness and cough influence lung function parameters, whereas chronic phlegm was not associated with

Earn CME accreditation by answering questions about this article. You will find these at the back of the printed copy of this issue or online at http://www.erj.ersjournals.com/current.shtml

AFFILIATIONS

*Lung Association Zurich,

"Division of Respiratory Medicine, University Children's Hospital,

+Biostatistics Unit, Institute of Social and Preventive Medicine, University of Zurich,

${ }^{\S}$ Division of Pulmonary Medicine, University Hospital, Zurich, and

\# Institute of Social and Preventive Medicine, University of Basel, Basel, Switzerland.

${ }^{f}$ Both authors contributed equally to the present article.

\section{CORRESPONDENCE}

D. Kuster

Lungenliga Zürich

Wilfriedstrasse 7

8032 Zürich

Switzerland

Fax: 41442682020

E-mail: projekte@lungenliga-zh.ch

Received:

July 202007

Accepted after revision:

November 172007

SUPPORT STATEMENT

Statistical analysis was funded by the Lung Association Zurich.

STATEMENT OF INTEREST

None declared. 
airway obstruction or reduced forced expiratory volume in one second (FEV1) in some surveys, suggesting that perhaps not all respiratory symptoms need to be accounted for when defining a healthy reference population used to derive reference values [3].

Most reference equations used in North America and Europe have been derived from studies that included relatively small numbers of individuals aged $>65$ yrs. Only a few sets of equations have been published for elderly lifetime nonsmokers of Caucasian-American origin [11-13]. Since international guidelines discourage the use of spirometry reference equations for ages or heights outside the range covered by the data that generated them, there is a need to collect lung function data from elderly persons $[2,14]$.

In the present study, the results provided are based on a large cross-sectional sample from a Central European population. The present study is unique in that empirically based reference equations of forced spirometry are presented for subjects aged $18-80$ yrs. The reference equations used in the present study for the means and the fifth percentiles as lower limits of normal range account for changes in the distribution of lung function with age and height. Reference values from the present study are compared for the entire age range with those from the Swiss Cohort Study on Air Pollution and Lung Diseases in Adults (SAPALDIA), those from the ECCS and those from the third National Health and Nutrition Examination Survey (NHANES III) [7, 15-17]. Reference values for elderly subjects are compared with other reference sets that were derived for individuals aged $>65$ yrs [11, 13, 17-19].

\section{METHODS}

In the present cross-sectional study, lung function test results collected by the "LuftiBus" team in the greater Zurich metropolitan area (Zurich, Switzerland) between December 2000 and August 2005 were analysed. The LuftiBus project is maintained by the Lung Association of Zurich. It consists of a bus equipped with two flow-sensing spirometers that tours mainly the greater Zurich area and offers spirometry measurements to the general public. Spirometry data are recorded electronically along with data from a standardised intervieweradministered questionnaire collecting basic information on the health and lifestyle of subjects. Lung function tests are charged at $10 \mathrm{CHF}$ to adults to cover the costs on a nonprofit basis.

\section{Reference population}

From a total of 20,460 subjects, 8,684 were included in the sample used to derive normal values for spirometric parameters (table 1). Subjects were excluded if they met at least one of the exclusion criteria (table 2). Never-smokers were defined as subjects with a cumulative smoking history of $<1$ pack-yr (a pack-yr is defined as years of smoking $\times$ the number of cigarettes smoked per day divided by 20). Due to the ongoing migration in Europe and mixture of ethnical backgrounds, and due to the very small proportion of non-Caucasian people in Switzerland, no exclusion was made based on race or nationality [20]. Thus, ethnicity was not assessed systematically for the whole study population. Ethnicity was recorded in a subset of 3,061 consecutive subjects of the reference sample (1,356 males and 1,705 females) measured in the years 2004 and 2005 and, thereof, non-Caucasian subjects accounted for 19 (1.1\%) females and $17(1.3 \%)$ males.

\begin{tabular}{lccc} 
TABLE 1 & Inclusion characteristics for study population \\
& Males & Females & Total \\
\hline $\begin{array}{l}\text { Subjects n } \\
\text { Health criteria } \\
\quad \text { satisfied }\end{array}$ & 9738 & 10722 & 20460 \\
$\begin{array}{l}\text { Never-smokers } \\
\text { All criteria satisfied }\end{array}$ & $4371(75.7)$ & $7803(72.8)$ & $15174(74.2)$ \\
\hline
\end{tabular}

Data are presented as $n(\%)$, unless otherwise stated.

\section{Spirometry}

During the time of data collection, the LuftiBus was equipped with two computerised pneumotachographs (SensorMedics ${ }^{\circledR}$ Vmax Legacy 20c spirometer run by Vision 7-2b software; VIASYS, Yorba Linda, CA, USA). The volume signal of the equipment was calibrated at least once daily with a 3-L syringe. Tests were performed in a sitting position according to American Thoracic Society (ATS) guidelines without nose-clips after an oral instruction by the technician $[2,14]$. Participants were assisted by eight specially trained lung function technicians who performed immediate on-screen evaluation of major acceptability criteria (including start, duration and end of test) in addition to the automated review performed by the computer software. As recommended by the ATS in 1994 [14], data that did not meet reproducibility criteria were not excluded, but subjects were asked to perform up to a maximum of eight manoeuvres in an attempt to obtain reproducible results. From a minimum of two acceptable tests, the largest forced vital capacity (FVC) and FEV1 were selected, regardless of the manoeuvre. All other parameters were taken from the trial with the largest sum of FVC and FEV1. Selfreported values for height were used.

\section{Statistical methods}

The methodology used by the SAPALDIA team was reproduced. In a first step, prediction equations for the mean were estimated. Equations for the fifth percentiles, which were the

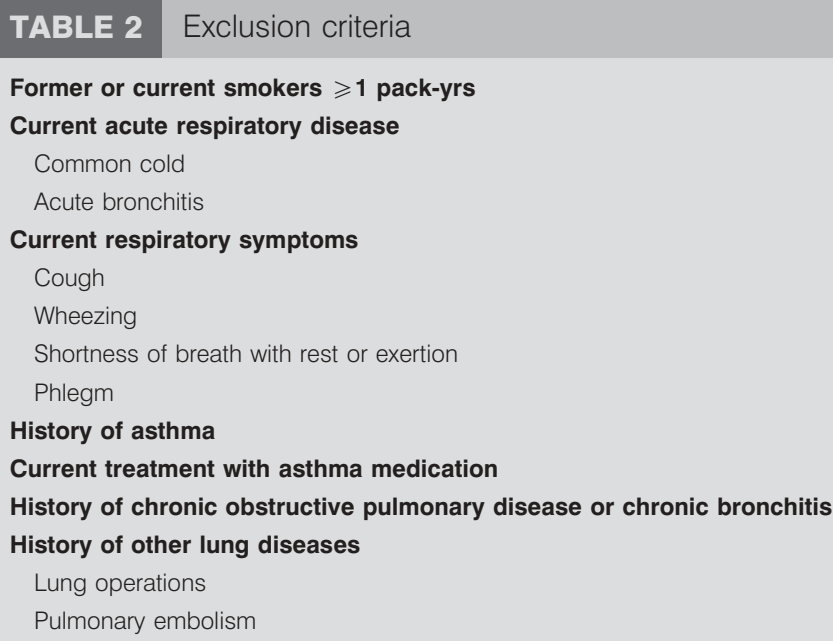


primary focus of interest as lower limits of the normal range, were then estimated from the residuals of the models for the mean. All regression models were stratified by sex. The methods have been described in detail previously $[15,16]$.

\section{Prediction equations for the mean}

To estimate equations for the mean, the natural logarithms of lung function variables were regressed against $\ln$ (height), age and quadratic function of age. The rationale for considering lung function variables on the logarithmic scale was the assumption that the dependency of average lung function (LF) on height $(\mathrm{H})$ and age $(\mathrm{A})$ is suitably described by a function of the form:

$$
\mathrm{LF}=\mathrm{H}^{\mathrm{c}} \times \mathrm{f}(\mathrm{A})
$$

Whereas estimating the exponent $c$ from the untransformed data requires the solution of a nonlinear regression problem, the logarithmic transformation of the equation turns the regression problem for $\mathrm{c}$ into a linear one. The piecewise quadratic model was only retained if its fit was significantly better than the one of a simple quadratic model defined over the entire interval. If such a simplified model proved to be sufficiently adequate, it was also tested whether or not the quadratic age term was statistically significant.

\section{Prediction equations for fifth percentiles}

The next step was to compute fifth percentiles according to a new method for estimating percentile curves using weighted $\mathrm{L}_{1}$ regression. Thus, instead of minimising the sum of squared residuals, a weighted sum of the absolute values of the residuals was minimised. These residuals were again regressed against age. If:

$$
y=\alpha+\beta \times A
$$

denotes the estimated regression line for the fifth percentile of

$$
\mathrm{r}=\ln (\text { LFobserved } / \text { LFpredicted })
$$

as a function of age, then;

$$
y=\text { LFpredicted } \times \exp (\alpha+\beta \times A)
$$

is an estimate of the fifth percentile of lung function for a given age. To test whether a linear age term was sufficient to describe the age dependency of the fifth percentile of $r$, an indicator variable $U$ was defined taking the value of 1 for residuals:

$$
r \leqslant \alpha+\beta \times A
$$

and the value 0 for residuals:

$$
r>\alpha+\beta \times A
$$

and a logistic regression model for $\mathrm{U}$ in terms of the covariates $\mathrm{A}$ and $\mathrm{A}^{2}$ was computed. The quadratic term did not reach statistical significance for any of the lung function parameters considered, thus suggesting that the model with the linear age term was sufficient throughout. In an analogous way, it could be verified that the fifth percentile of $\mathrm{r}$ did not significantly depend on the height of the individual.

\section{Comparisons of reference equations}

The newly derived reference equations were compared with those most widely used in Europe (ECCS) and the USA
(NHANES III), as well as the most recent Swiss reference values (SAPALDIA) [8, 15-17]. In addition, in order to especially address the concerns that might arise due to the possible over-reporting of height in elderly patients, reference values of $65-80$-yr-old subjects were compared with several sets of reference equations that were recently published for this population [11, 13, 17-19].

\section{RESULTS}

The main characteristics of the study population are shown in table 3. Demographic data of the 8,684 subjects show an overrepresentation of females satisfying the inclusion criteria because females were more likely to have never smoked than males and females were, to a lesser extent, over-represented in the study sample.

The prediction equations for the mean of the lung function variables are displayed in table 4 as:

$$
\mathrm{LF}=\exp \left(\mathrm{a}+\mathrm{b} \times \ln (\mathrm{H})+\mathrm{c}_{1} \times \mathrm{A}+\mathrm{c}_{2} \times \mathrm{A}^{2}\right)
$$

where LF represents any of the lung function variables measured (FVC, FEV1, FEV1/FVC, maximal instantaneous forced expiratory flow when $75 \%$ of the FVC remains to be exhaled (MEF75), maximal instantaneous forced expiratory flow when $50 \%$ of the FVC remains to be exhaled (MEF50), and maximal instantaneous forced expiratory flow when $25 \%$ of the FVC remains to be exhaled (MEF25)). This equation is equivalent to:

$$
\ln (\mathrm{LF})=\mathrm{a}+\mathrm{b} \times \ln (\mathrm{H})+\mathrm{c}_{1} \times \mathrm{A}+\mathrm{c}_{2} \times \mathrm{A}^{2}
$$

The equations for the fifth percentiles, which are generally recommended as a lower limit of the normal range, are displayed in table 5. They are of the same form as those for the

\begin{tabular}{|c|c|c|}
\hline \multirow[t]{2}{*}{ TABLE 3} & \multicolumn{2}{|c|}{$\begin{array}{l}\text { Height characteristics and age distribution of } \\
\text { reference sample }\end{array}$} \\
\hline & Males & Females \\
\hline Subjects n & 3512 & 5172 \\
\hline Height $^{\#}$ cm & $176.3 \pm 7.4$ & $163.3 \pm 6.8$ \\
\hline Age $^{\#}$ yrs & $47.3(18.2)$ & $52.9(17.5)$ \\
\hline$<30$ & $742(21.1)$ & $625(12.1)$ \\
\hline 30-39 & 525 (14.9) & 649 (12.5) \\
\hline $40-49$ & 659 (18.8) & 821 (15.9) \\
\hline $50-59$ & 592 (16.9) & $936(18.1)$ \\
\hline $60-69$ & $504(14.4)$ & 1119 (21.6) \\
\hline $70-79$ & $376(10.7)$ & $822(15.9)$ \\
\hline$>79$ & $114(3.2)$ & $200(3.9)$ \\
\hline
\end{tabular}
mean. The ranges of application for these reference equations are ages $18-80$ yrs and heights of 140-200 and 130-190 cm in males and females, respectively.

The choice of two age intervals (one for the ages 18-25 yrs and one for the interval $>25$ yrs) was suggested by the ECCS, who had modelled lung function by a piecewise linear function of age. The SAPALDIA team had found that, even with a 


\begin{tabular}{|c|c|c|}
\hline \multirow[t]{2}{*}{ TABLE 4} & \multicolumn{2}{|l|}{$\begin{array}{l}\text { Prediction equations for the means of lung } \\
\text { function variables }\end{array}$} \\
\hline & Equation & $\mathbf{R}^{2 \#}$ \\
\hline \multicolumn{3}{|l|}{ Males } \\
\hline FVC L & $\exp \left(-10.258+2.280 \ln (H)+0.00676 \mathrm{~A}-0.000124 \mathrm{~A}^{2}\right)$ & 0.549 \\
\hline $\mathrm{FEV}_{1} \mathrm{~L}$ & $\exp \left(-8.957+2.014 \ln (H)+0.00281 A-0.000105 A^{2}\right)$ & 0.639 \\
\hline MEF75 L.S $\mathrm{S}^{-1}$ & $\exp \left(-2.227+0.812 \ln (H)+0.00977 A-0.000132 A^{2}\right)$ & 0.108 \\
\hline MEF50 L.S ${ }^{-1}$ & $\exp \left(-3.055+0.911 \ln (\mathrm{H})+0.00249 \mathrm{~A}-0.000109 \mathrm{~A}^{2}\right)$ & 0.226 \\
\hline $\mathrm{MEF}_{25} \mathrm{~L} \cdot \mathrm{S}^{-1}$ & $\exp \left(-3.970+1.009 \ln (H)-0.01645 A-0.000020 A^{2}\right)$ & 0.419 \\
\hline $\mathrm{FEV}_{1 / \mathrm{FVC}} \%$ & $\exp \left(+6.291-0.341 \ln (H)-0.00441 \mathrm{~A}+0.000026 \mathrm{~A}^{2}\right)$ & 0.126 \\
\hline$P E F L \cdot s^{-1}$ & $\exp \left(-3.760+1.170 \ln (\mathrm{H})+0.00706 \mathrm{~A}-0.000110 \mathrm{~A}^{2}\right)$ & 0.233 \\
\hline \multicolumn{3}{|l|}{ Females } \\
\hline FVC L & $\exp \left(-9.069+2.013 \ln (\mathrm{H})+0.00847 \mathrm{~A}-0.000155 \mathrm{~A}^{2}\right)$ & 0.562 \\
\hline FEV 1 L & $\exp \left(-8.397+1.865 \ln (\mathrm{H})+0.00570 \mathrm{~A}-0.000150 \mathrm{~A}^{2}\right)$ & 0.526 \\
\hline $\mathrm{MEF} 75 \mathrm{~L} \cdot \mathrm{S}^{-1}$ & $\exp \left(-2.716+0.867 \ln (\mathrm{H})+0.00963 \mathrm{~A}-0.000140 \mathrm{~A}^{2}\right)$ & 0.184 \\
\hline MEF50 L.S ${ }^{-1}$ & $\exp \left(-2.131+0.674 \ln (\mathrm{H})+0.00895 \mathrm{~A}-0.000180 \mathrm{~A}^{2}\right)$ & 0.253 \\
\hline$M E F 25 L \cdot S^{-1}$ & $\exp \left(-4.861+1.145 \ln (\mathrm{H})-0.01120 \mathrm{~A}-0.000096 \mathrm{~A}^{2}\right)$ & 0.423 \\
\hline $\mathrm{FEV}_{1} / \mathrm{FVC} \%$ & $\exp \left(+5.637-0.219 \ln (H)-0.00249 A+0.000004 A^{2}\right)$ & 0.039 \\
\hline$P E F L \cdot S^{-1}$ & $\exp \left(-4.794+1.316 \ln (\mathrm{H})+0.00926 \mathrm{~A}-0.000143 \mathrm{~A}^{2}\right)$ & 0.329 \\
\hline $\begin{array}{l}\text { FVC: forced vit } \\
\text { MEF25 or } 50 \text { or } 75 \\
75 \% \text { of the FVC } \\
\text { H: height }(\mathrm{cm}) \text {; }\end{array}$ & $\begin{array}{l}\text { tal capacity; FEV1: forced expiratory volume in one s } \\
\text { 5: maximal instantaneous forced expiratory flow when } 25 \\
\text { remains to be exhaled, respectively; PEF: peak expirator } \\
\text { A: age (yrs); } \exp (\mathrm{x}) \text { : } \mathrm{e}^{\mathrm{x}} \text {. \# : fraction of explained variance }\end{array}$ & $\begin{array}{l}\text { cond; } \\
50 \text { or } \\
\text { flow; }\end{array}$ \\
\hline
\end{tabular}

quadratic function of age, a separate model for subjects aged $<25$ yrs was warranted [8, 21]. However, in the present study, separate equations did not fit the data significantly better than a single equation. Results for each lung function variable refer to participants who performed the tests according to ATS quality criteria [14].

Comparisons with the reference equations provided by the ECCS for 18-70-yr-old subjects and the recently published Swiss values for subjects aged 18-60 yrs are shown in figure 1 for males and in figure 2 for females [15]. However, the present sample included a considerable number of subjects aged $>70 \mathrm{yrs}$, so that the estimation of reference equations could be extended to the age of $80 \mathrm{yrs}$.

In males as well as in females, the volumes predicted by reference equations for the fifth percentile of FEV1 from the present study are higher than those from the ECCS throughout. In 50-yr-old males (height $175 \mathrm{~cm}$ ), lower limits of normal for FEV1 are underestimated by $198 \mathrm{~mL}$, those of 50-yr-old females (height $165 \mathrm{~cm}$ ) by $191 \mathrm{~mL}$ by the ECCS reference equations in comparison to the LuftiBus data. In 30-yr-old males (height $175 \mathrm{~cm}$ ) and females (height $165 \mathrm{~cm}$ ), lung volumes predicted by the present study's reference values are 86 and $101 \mathrm{~mL}$ higher than those from the ECCS, respectively. However, the difference practically vanishes at age $70 \mathrm{yrs}$, indicating that the reference values for FEV1 provided by the ECCS equations underestimate the decline of lung volumes in elderly females.

For FVC, the present study's reference equations for the fifth percentile provide the lowest values in males aged 18-27 yrs. Lower limits of normal for FVC are underestimated by the ECCS reference equations in comparison with the LuftiBus

\begin{tabular}{|c|c|}
\hline TABLE 5 & $\begin{array}{l}\text { Prediction equations for the fifth percentiles of } \\
\text { lung function variables }\end{array}$ \\
\hline & Equation \\
\hline \multicolumn{2}{|l|}{ Males } \\
\hline FVC L & $\exp \left(-10.437+2.280 \ln (H)+0.00532 A-0.000124 A^{2}\right)$ \\
\hline FEV 1 L & $\exp \left(-9.111+2.014 \ln (H)+0.00102 A-0.000105 A^{2}\right)$ \\
\hline MEF75 L.S $S^{-1}$ & $\exp \left(-2.524+0.812 \ln (\mathrm{H})+0.00661 \mathrm{~A}-0.000132 \mathrm{~A}^{2}\right)$ \\
\hline MEF50 L.S $\mathrm{S}^{-1}$ & $\exp \left(-3.338+0.911 \ln (H)-0.00289 A-0.000109 A^{2}\right)$ \\
\hline MEF25 L·S $\mathrm{S}^{-1}$ & $\exp \left(-4.262+1.009 \ln (H)-0.02485 A-0.000020 A^{2}\right)$ \\
\hline $\mathrm{FEV}_{1} / \mathrm{FVC} \%$ & $\exp \left(+6.180-0.341 \ln (\mathrm{H})-0.00529 \mathrm{~A}+0.000026 \mathrm{~A}^{2}\right)$ \\
\hline PEF L. $S^{-1}$ & $\exp \left(-3.992+1.170 \ln (H)+0.00493 \mathrm{~A}-0.000110 \mathrm{~A}^{2}\right)$ \\
\hline \multicolumn{2}{|l|}{ Females } \\
\hline FVC L & $\exp \left(-9.213+2.013 \ln (H)+0.00616 \mathrm{~A}-0.000155 \mathrm{~A}^{2}\right)$ \\
\hline $\mathrm{FEV}_{1} \mathrm{~L}$ & $\exp \left(-8.521+1.865 \ln (\mathrm{H})+0.00357 \mathrm{~A}-0.000150 \mathrm{~A}^{2}\right)$ \\
\hline MEF75 L.S ${ }^{-1}$ & $\exp \left(-2.977+0.867 \ln (\mathrm{H})+0.00698 \mathrm{~A}-0.000140 \mathrm{~A}^{2}\right)$ \\
\hline MEF50 L.S $S^{-1}$ & $\exp \left(-2.374+0.674 \ln (\mathrm{H})+0.00330 \mathrm{~A}-0.000180 \mathrm{~A}^{2}\right)$ \\
\hline $\mathrm{MEF} 25 \mathrm{~L} \cdot \mathrm{S}^{-1}$ & $\exp \left(-5.140+1.145 \ln (H)-0.02002 A-0.000096 A^{2}\right)$ \\
\hline $\mathrm{FEV}_{1} / \mathrm{FVC} \%$ & $\exp \left(+5.524-0.219 \ln (H)-0.00313 A+0.000004 A^{2}\right)$ \\
\hline$P E F L \cdot s^{-1}$ & $\exp \left(-5.032+1.316 \ln (H)+0.00767 A-0.000143 A^{2}\right)$ \\
\hline
\end{tabular}

FVC: forced vital capacity; FEV1: forced expiratory volume in one second; MEF25 or 50 or 75 : maximal instantaneous forced expiratory flow when 25,50 or $75 \%$ of the FVC remains to be exhaled, respectively; PEF: peak expiratory flow: $H$ : height $(\mathrm{cm}) ; A$ : age $(y r s) ; \exp (x): e^{x} .{ }^{\#}$ : fraction of explained variance.

data by $210 \mathrm{~mL}$ in 50 -yr-old males (height $175 \mathrm{~cm}$ ) and by $270 \mathrm{~mL}$ in 50-yr-old females (height $165 \mathrm{~cm}$ ). In 30-yr-old males (height $175 \mathrm{~cm}$ ) and females (height $165 \mathrm{~cm}$ ), lung volumes predicted by the present study's reference values are 42 and $107 \mathrm{~mL}$ higher than those from the ECCS, respectively. In both sexes, the decline of FVC with age is steeper than predicted by the ECCS equations.

Reference equations provided by SAPALDIA give the highest values for fifth percentiles of FEV1 and FVC throughout, with the lower limits of NHANES III showing almost identical values. By contrast, the present study's values for the lower limit of normal for MEF75 in all age groups of both sexes are highest among the reference data compared. For MEF25, the present study's data indicate that the decline of late flows with age is not as steep as suggested by the ECCS and SAPALDIA.

Figure 3 illustrates the decline of FVC with age for male subjects aged 65-80 yrs compared with published reference values for elderly subjects [11, 13, 17-19]. Regarding the decline of lung volumes with age, the present data are in line with other published reference values (i.e. corresponding curves run almost parallel), indicating that over-reporting of stated height in elderly subjects has not occurred to a significant extent.

\section{DISCUSSION}

The present authors derived reference equations for screening spirometry from data collected in a screening programme (LuftiBus) among 8,684 healthy, never-smoking volunteers in the period 2000-2005. Fifth percentiles as lower limits of normal were derived according to a new statistical method [16]. 

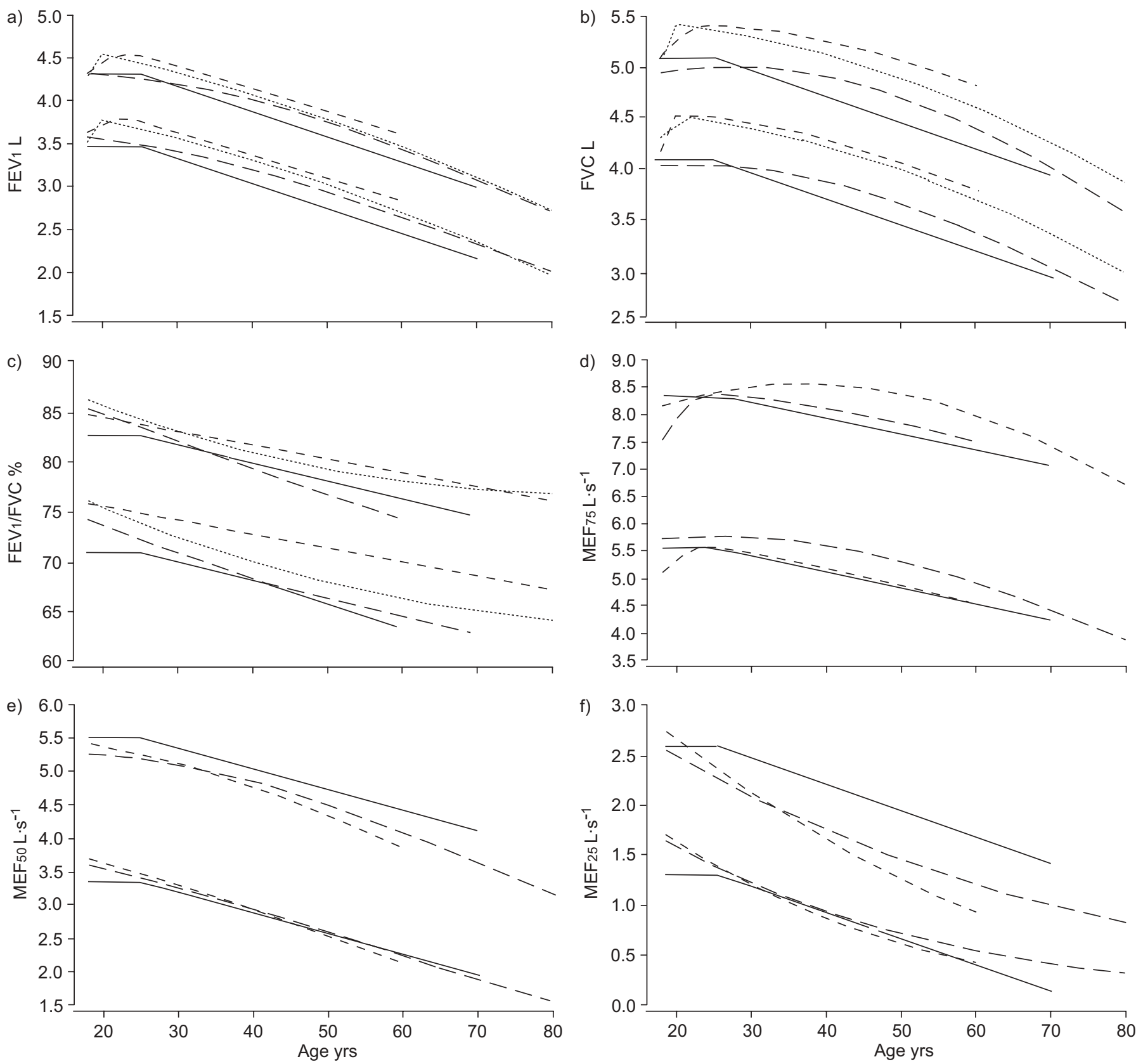

FIGURE 1. Age dependency of mean values and fifth percentiles of a) forced expiratory volume in one second (FEV 1 ), b) forced vital capacity (FVC), C) FEV $1 / F V C$ d) maximal instantaneous forced expiratory flow when $75 \%$ of the FVC remains to be exhaled (MEF75), e) MEF when $50 \%$ of the FVC remains to be exhaled (MEF50), and f) MEF when 25\% of the FVC remains to be exhaled (MEF25) in males (height $175 \mathrm{~cm}$ ) in comparison with published reference values. ——: European Community of Coal and Steel; -----: Swiss Cohort Study on Air Pollution and Lung Diseases in Adults; …...... third National Health and Nutrition Examination Survey; -- - --: LuftiBus.

For FVC and FEV1, the present study's reference equations for the lower limit of normal provide values that are lower than the ones from SAPALDIA and NHANES III but higher than the ones from the ECCS in the age range 30-70 yrs. The present study's reference equations provide the lowest values in males aged 18-27 yrs for FVC only.

For both sexes, the decline of FVC in elderly subjects appears to be underestimated by the equations from the ECCS. The present study's reference values also predict a steeper decline of FEV1 in elderly females. By contrast, the present study's curves for the decline of MEF25 with age are not as steep as the ones from the ECCS and SAPALDIA.

The present study's equations differ from those derived by the ECCS with regard to their mathematical form and to the nature of the underlying data. The ECCS reference equations were obtained by summarising published regression equations from older surveys published between the 1950s and 1980s that employed different instruments [8]. 

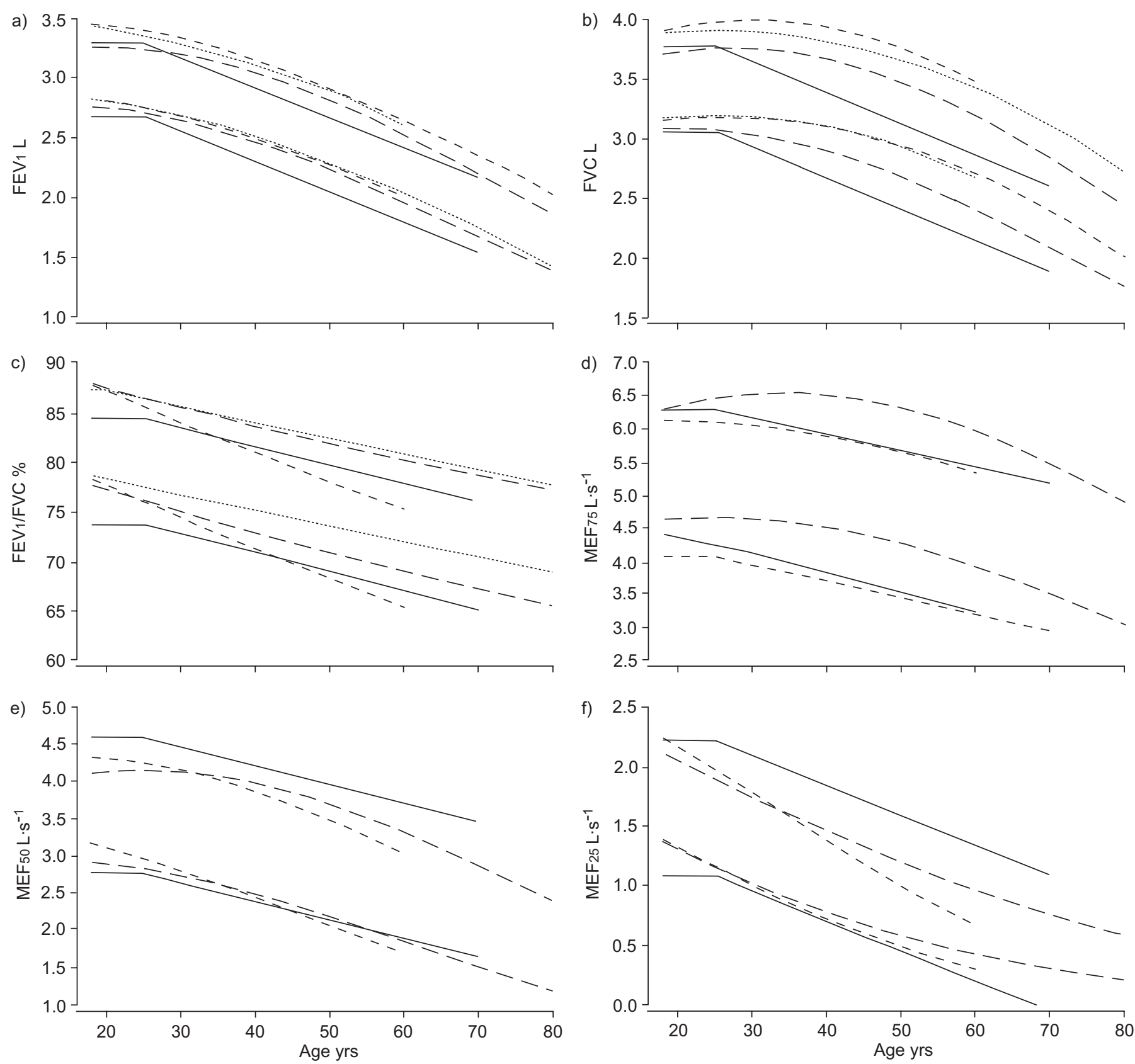

FIGURE 2. Age dependency of mean values and fifth percentiles of a) forced expiratory volume in one second (FEV1), b) forced vital capacity (FVC), C) FEV $1 / F V C$ d) maximal instantaneous forced expiratory flow when $75 \%$ of the FVC remains to be exhaled (MEF75), e) MEF when 50\% of the FVC remains to be exhaled (MEF50), and f) MEF when 25\% of the FVC remains to be exhaled (MEF25) in females (height $165 \mathrm{~cm}$ ) in comparison with published reference values. ——: European Community of Coal and Steel; -----: Swiss Cohort Study on Air Pollution and Lung Diseases in Adults; …...... third National Health and Nutrition Examination Survey; - - - -: LuftiBus.

There are several differences in the methods applied in the SAPALDIA and the LuftiBus studies, both of which evaluated samples of the Swiss population. Subjects participating in the LuftiBus project were volunteers who were charged for the test on a nonprofit basis. In SAPALDIA, participants were randomly selected among the inhabitants of the study sites. This might result in some selection bias in the present study, despite the large population sample with a proper distribution of body height.
It has been demonstrated that using different spirometers may account for systematic deviations of lung function parameters of $>5 \%$. The systematic differences may be due to both hardware and software [22]. Thus, the systematically higher lung volumes derived by SAPALDIA could be originating from a systematic bias due to different equipment.

As proposed by the ATS, lung function tests that did not meet reproducibility criteria were not excluded from the present 

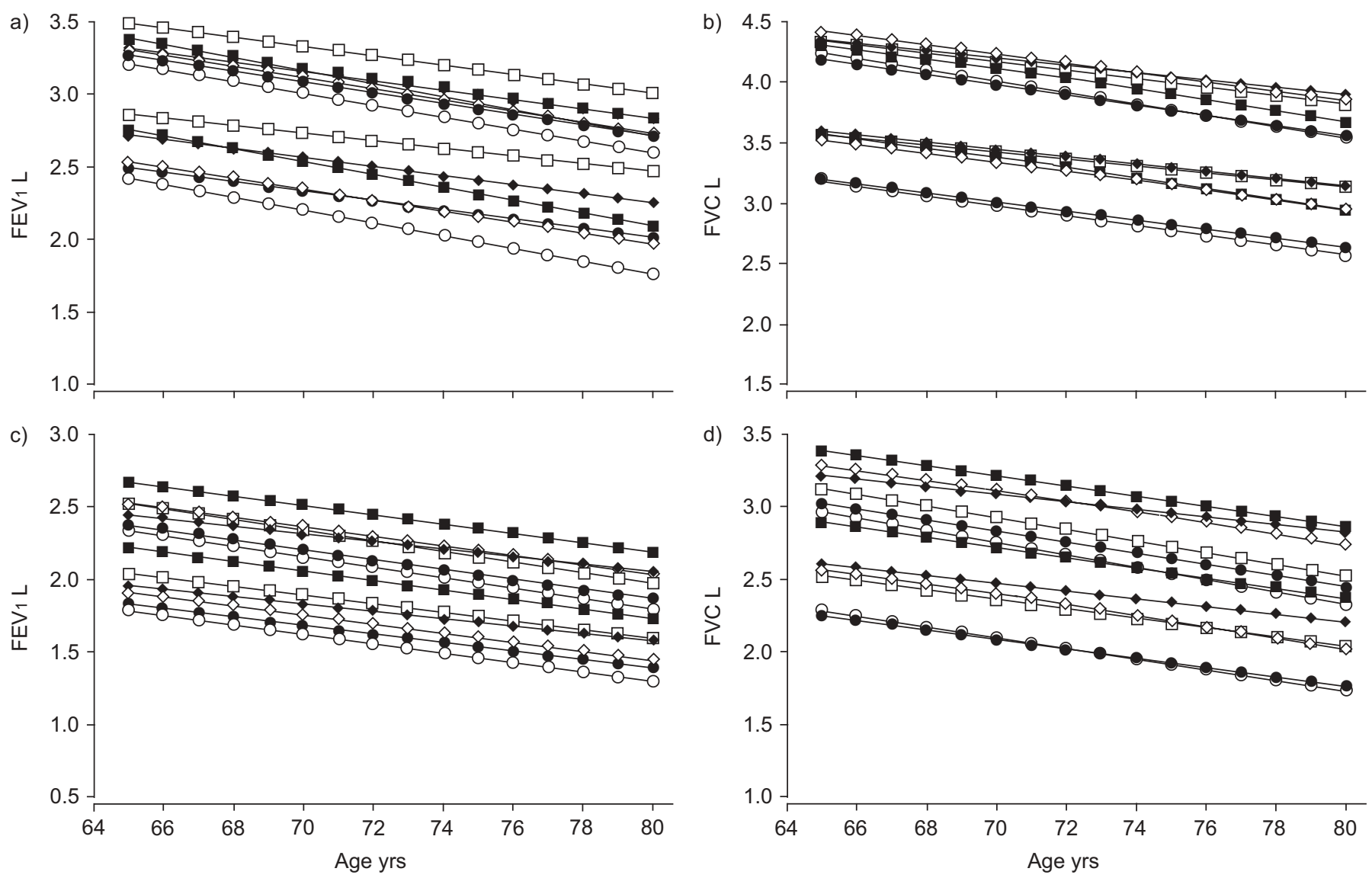

FIGURE 3. Age dependency of mean values and fifth percentiles of a) forced expiratory volume in one second (FEV1) and b) forced vital capacity (FVC) in males (height $175 \mathrm{~cm}$ ) and of C) FEV1 and d) FVC in females (height $165 \mathrm{~cm}, 55 \mathrm{~kg}$ ) aged 65-80 yrs in comparison with published reference values. [ : GARCIA-Rio et al. [11]; $\square$ : Langhammer et al. [18]; •: LuftiBus; O: Falaschetti et al. [19]; • McDonnell et al. [13]; $\diamond$ : third National Health and Nutrition Examination Survey.

investigation [14]. In contrast, in SAPALDIA, only reproducible lung function tests results were evaluated. This probably results in systematically higher lung volumes.

Another issue could be the origin of the study population. Subjects from the present study population originate from the greater Zurich metropolitan area, whereas SAPALDIA included subjects from rural as well as from urban Swiss areas. Local exposure to traffic has been demonstrated to have adverse effects on children's lung development, which could result in lung function deficits persisting into later life [23]. This might even have resulted in differences between the lung function tests of the two different birth cohorts of the SAPALDIA and the LuftiBus project. There is evidence that pollution from fossil fuel combustion is associated with decrements in lung function, which might, in part, explain the lower values in the present study having been derived from subjects predominantly living in urban areas [24].

The present study has several limitations as data include asymptomatic never-smokers without known pulmonary disease. Moreover, no clinical or chest radiographical examinations were performed, which might result in the inclusion of some patients with unknown asymptomatic lung disease. There are limited possibilities to quantify factors that may influence lung function, such as occupational exposure, passive smoking and the effect of chest injuries or chest surgical interventions. The nature of the evaluation did not account for all these parameters in detail. Additionally, access to medical data was not possible, except for those provided by the study subjects themselves. The current authors believe that the exclusion of subjects suffering from respiratory symptoms, such as dyspnoea (with or without exercise) or cough might have resulted in the exclusion of a large proportion of those patients. However, in this regard, the present study is in line with most other studies having published reference equations for lung function. Smoking status was quantified as "cumulative numbers of pack-yrs" and never-smokers were defined as subjects with a cumulative smoking history of $<1$ pack-yr. As it has been shown that a cumulative smoking history of $\leqslant 5$ pack-yrs barely influences lung volumes and, due to a lack of evidence for other thresholds in the current literature, not excluding occasional cigarette smokers, pipe smokers or nontobacco smokers with a cumulative history of $<1$ pack-yr might be acceptable for deriving reference equations [25].

Regardless of the fact that deriving reference equations from large groups of volunteers is thought to be acceptable, provided that criteria for normal selection and proper distribution of anthropometric characteristics are satisfied, some selection bias might have crept in [10]. In particular, the 
charge for the test might have kept certain groups of individuals from participating.

Using self-reported height, or estimating height from arm span is regarded as an option in the clinical setting when spirometry is performed in patients who have conditions that hamper the standing position [10]. Self-reported height was shown to give an accurate representation of true values in different populations, but age has been stated to be an important factor for misreporting height [26-30]. Height overestimation in the elderly is congruent with age-related corporal changes. The present data concerning the decline of FVC with age, however, are consistent with those from other publications that used measured height to derive reference equations for subjects aged 65-85 yrs [11, 13, 17-19].

Body mass index (BMI) has been shown to have significant effects on all the lung volumes, especially the functional residual capacity and expiratory reserve volume [31]. As a rule of thumb, lung volumes decrease as body weight increases. Thus, attempts have been made to introduce BMI as an independent variable in newly derived reference equations [32]. In a subset of the present study's subjects, the current authors assessed whether BMI could be included as a predictor of lung function. Thereby, BMI was shown not to influence lung volumes. Moreover, in analogy to height, self-reported weight was recorded in the present study. Due to a tendency of study participants to over-report height and, to a greater extent, underreport weight, stated BMI was demonstrated to be systematically underestimated in various studies [28, 33]. Thus, the current authors believe that using self-reported BMI is of limited value for deriving reference equations.

As stated in the 1994 update of the ATS guidelines for standardisation of spirometry [14], nose-clips do not appreciably influence the FVC when using the open-circuit technique. However, their use was encouraged, especially when performing a slow vital capacity manoeuvre, because some people breathe through the nose. The use of nose-clips was considered mandatory if a closed-circuit technique with carbon dioxide absorption was used. Guidelines from 2005 [34], published at the end of data collection for the LuftiBus study, recommend the use of a nose-clip or manual occlusion of the nares. It has been demonstrated that the application of a nose-clip has no significant impact on measurement of peak expiratory flow, but its importance for the other lung function parameters, to the present authors' knowledge, has not been studied [35]. That the present study's lung function tests were performed without a nose-clip might, nevertheless, partly explain the observed differences with the SAPALDIA reference equations, since a certain loss of air through the nasal route is likely to have occurred at least in some subjects.

It was proposed that reference equations should be derived from a population most similar to that for which the equations are to be used and based on measurements obtained by the same instruments and testing procedures [32]. Since the methodology used in the LuftiBus project mirrors the methods used in daily practice, where measurement of height and application of a nose-clip is often abandoned, the present results may thus provide a valuable contribution to lung function testing within a routine outpatient setting. The present study in particular meets the major need for updated and empirically derived reference equations of forced spirometry for subjects aged 65-80 yrs.

\section{ACKNOWLEDGEMENTS}

The authors acknowledge and thank the Lung Association Zurich (Switzerland) for providing the spirometry data.

\section{REFERENCES}

1 Becklake MR. Concepts of normality applied to the measurement of lung function. Am J Med 1986; 80: 1158-1164.

2 American Thoracic Society. Lung function testing: selection of reference values and interpretative strategies. Am Rev Respir Dis 1991; 144: 1202-1218.

3 Johannessen A, Omenaas ER, Eide GE, Bakke P, Gulsvik A. Feasible and simple exclusion criteria for pulmonary reference populations. Thorax 2007; 62: 792-798.

4 Xu X, Laird N, Dockery DW, Schouten JP, Rijcken B, Weiss ST. Age, period, and cohort effects on pulmonary function in a 24-year longitudinal study. Am J Epidemiol 1995; 141: 554-566.

5 Standardization of spirometry - 1987 update. American Thoracic Society. Am Rev Respir Dis 1987; 136: 1285-1298.

6 Hankinson JL. Instrumentation for spirometry. Occup Med 1993; 8: 397-407.

7 Quanjer PH. Standardized lung function testing. Bull Eur Physiopathol Respir 1983; 19: Suppl. 5, 1-95.

8 Quanjer PH, Tammeling GJ, Cotes JE, Pedersen OF, Peslin R, Yernault JC. Lung volumes and forced ventilatory flows. Report Working Party Standardization of Lung Function Tests, European Community for Steel and Coal. Official Statement of the European Respiratory Society. Eur Respir J 1993; 6: Suppl. 16, S5-S40.

9 Roca J, Burgos F, Sunyer J, et al. References values for forced spirometry. Group of the European Community Respiratory Health Survey. Eur Respir J 1998; 11: 1354-1362.

10 Pellegrino R, Viegi G, Brusasco V, et al. Interpretative strategies for lung function tests. Eur Respir J 2005; 26: 948-968.

11 Garcia-Rio F, Pino JM, Dorgham A, Alonso A, Villamor J. Spirometric reference equations for European females and males aged 65-85 yrs. Eur Respir J 2004; 24: 397-405.

12 Enright PL, Kronmal RA, Higgins M, Schenker M, Haponik EF. Spirometry reference values for women and men 65 to 85 years of age. Cardiovascular health study. Am Rev Respir Dis 1993; 147: 125-133.

13 McDonnell WF, Enright PL, Abbey DE, et al. Spirometric reference equations for older adults. Respir Med 1998; 92: 914-921.

14 Standardization of Spirometry, 1994 Update. American Thoracic Society. Am J Respir Crit Care Med 1995; 152: 1107-1136.

15 Brandli O, Schindler C, Kunzli N, Keller R, Perruchoud AP. Lung function in healthy never smoking adults: reference values and lower limits of normal of a Swiss population. Thorax 1996; 51: 277-283.

16 Brandli O, Schindler C, Leuenberger $\mathrm{PH}$, et al. Reestimated equations for 5th percentiles of lung function variables. Thorax 2000; 55: 172-174. 
17 Hankinson JL, Odencrantz JR, Fedan KB. Spirometric reference values from a sample of the general U.S. population. Am J Respir Crit Care Med 1999; 159: 179-187.

18 Langhammer A, Johnsen R, Gulsvik A, Holmen TL, Bjermer L. Forced spirometry reference values for Norwegian adults: the Bronchial Obstruction in NordTrondelag Study. Eur Respir J 2001; 18: 770-779.

19 Falaschetti E, Laiho J, Primatesta P, Purdon S. Prediction equations for normal and low lung function from the Health Survey for England. Eur Respir J 2004; 23: 456-463.

20 Kiviranta K, Haahtela T. Caucasian race and lung function: time to revisit the racial groups used in reference values. Eur Respir J 2006; 28: 1280.

21 Robbins DR, Enright PL, Sherrill DL. Lung function development in young adults: is there a plateau phase? Eur Respir J 1995; 8: 768-772.

22 Kunzli N, Kuna-Dibbert B, Keidel D, et al. Longitudinal validity of spirometers - a challenge in longitudinal studies. Swiss Med Wkly 2005; 135: 503-508.

23 Gauderman WJ, Vora H, McConnell R, et al. Effect of exposure to traffic on lung development from 10 to 18 years of age: a cohort study. Lancet 2007; 369: 571-577.

24 Ackermann-Liebrich U, Leuenberger P, Schwartz J, et al. Lung function and long term exposure to air pollutants in Switzerland. Study on Air Pollution and Lung Diseases in Adults (SAPALDIA) Team. Am J Respir Crit Care Med 1997; 155: 122-129.

25 Pistelli R, Bellia V, Catalano F, Antonelli Incalzi R, Scichilone N, Rengo F. Spirometry reference values for women and men aged 65-85 living in southern Europe: the effect of health outcomes. Respiration 2003; 70: 484-489.
26 Bolton-Smith C, Woodward M, Tunstall-Pedoe H, Morrison $\mathrm{C}$. Accuracy of the estimated prevalence of obesity from self reported height and weight in an adult Scottish population. J Epidemiol Community Health 2000; 54: 143-148.

27 Wada K, Tamakoshi K, Tsunekawa T, et al. Validity of selfreported height and weight in a Japanese workplace population. Int J Obes (London) 2005; 29: 1093-1099.

28 Nyholm M, Gullberg B, Merlo J, Lundqvist-Persson C, Rastam L, Lindblad U. The validity of obesity based on self-reported weight and height: implications for population studies. Obesity 2007; 15: 197-208.

29 Spencer EA, Appleby PN, Davey GK, Key TJ. Validity of self-reported height and weight in 4808 EPIC-Oxford participants. Public Health Nutr 2002; 5: 561-565.

30 Avila-Funes JA, Gutierrez-Robledo LM, Ponce De Leon Rosales S. Validity of height and weight self-report in Mexican adults: results from the national health and aging study. J Nutr Health Aging 2004; 8: 355-361.

31 Jones RL, Nzekwu MM. The effects of body mass index on lung volumes. Chest 2006; 130: 827-833.

32 Pistelli F, Bottai M, Carrozzi L, et al. Reference equations for spirometry from a general population sample in central Italy. Respir Med 2007; 101: 814-825.

33 McAdams MA, Van Dam RM, Hu FB. Comparison of selfreported and measured BMI as correlates of disease markers in US adults. Obesity 2007; 15: 188-196.

34 Miller MR, Hankinson J, Brusasco V, et al. Standardisation of spirometry. Eur Respir J 2005; 26: 319-338.

35 Vaswani R, Moy R, Vaswani SK. Evaluation of factors affecting peak expiratory flow in healthy adults: is it necessary to stand up? J Asthma 2005; 42: 793-794. 